\title{
Legal Analysis of the Exemption of Iranian Red Crescent Relief Workers from Compensation for Traffic Accident Injuries \\ Mohammad Abedi ${ }^{1} \mathbb{D}$, Mahmoud Arefi $\operatorname{Rad}^{2} \mathbb{D}$
}

Date of submission: 16 Aug. $2020 \quad$ Date of acceptance: 24 Aug. 2021

\section{Original Article}

\section{Abstract}

INTRODUCTION: The main activities of the Red Crescent rescuers are to rescue and release the injured. Most of the actions of these forces in road accidents cause damage to the body and rights of injured persons and third parties. These damages, which are required to carry out the activities of the relief force, are allowed subject to the normal damage; however, they are responsible for the damages that result from their indulgence and misappropriation. The main question is "What are the legal principles of exemption of relief workers from civil liability and how is it possible to combine the protection of the rights of the victims toward their bodies, lives, and property with supporting the good intentions and actions of the aid workers and performing their legal duties?

METHODS: This descriptive-analytical research describes the subjects or phenomena and their conditions and elements. Considering that to conduct research and explain the content, the provision of legal analysis is based on the analytical method, the method of data analysis is also based on the logical analysis. In this research, documents at traditional and digital libraries were used for data collection and note-taking was employed as the tool to gather data.

FINDINGS: This study, through contrasting the two ideas of protecting aid workers and the rights of victims to physical integrity, aimed to destabilize the relief workers' exemption based on such principles as beneficence, rule of law, urgency, and benevolent intervention and determine the limits and conditions of such exemption to ensure that the guaranteed rights of the injured individuals are not violated on their bodies and property.

CONCLUSION: It seems that the rule of law is the only basis that can always justify the relief workers' exemption from civil liability and other justifiable factors cannot always be compatible with the situation of relief workers. According to the rule, beneficence, the rule of law, benevolent intervention, and urgency can be considered factors in exempting relief workers. However, matching the situation of the rescuers with the justifiable factors shows that the main basis of the rescuers' exemption is the rule of law, which gives them the authority and duty to carry out rescue operations, and the necessary damages to rescue the injured is based on the rule of "permission in the object results in permission in its consequences".

Keywords: Benevolent Intervention; Fault; Justifiable Factors of Responsibility; Red Crescent Relief Workers; Rule of Law; Urgency.

How to cite this article: Abedi M, Arefi Rad M. Legal Analysis of the Exemption of Iran Red Crescent Relief Workers from Compensation for Traffic Accident Injuries. Sci J Rescue Relief 2021; 13(3): 177-86.

\section{Introduction}

$\mathrm{n}$ religious teachings and unwritten moral rules, there is a lot of advice to help all kinds of people, and there are many people who have dedicated their lives to helping people.

In some organizations, such as the Red Crescent, volunteer rescuers risk their lives in the face of disasters and put their lives at stake to save the lives or properties of others (1). The basics of helping others are originated from two principles, namely one's conscience and religious teachings. According to verse 32 of Surah Ma'idah, "If anyone saved a life, it would be as if he saved the life of the whole people." The audience of the verse is all human beings; in other words, there is no talk of saving the life of a believer, nor is there any emphasis on the believer as the only person responsible to perform this (2).

1- Assistant Professor, Department of Private Law, Ferdowsi University of Mashhad, Mashhad, Iran

2- Graduate of Private Law and Judge of Justice, Mashhad, Iran

Correspondence to: Mohammad Abedi, Email: dr.m.abedi@um.ac.ir 
Rescuing injured people in accidents, especially traffic accidents, is sometimes involved with damaging the injured person's or a third party's property and causing more physical injuries to the injured people during rescue operations. In order to realize civil liability, the existence of fault and the customary attribution of the damage are not avoidable (3); however, there are some factors that remove the description of the fault from the harmful act and lead to the exemption of the damage factor.

A person who performs an action according to the law and, as a result, the action causes damage to another person is not necessarily a responsible. A person who is in a position of kindness to another should not be morally or religiously reprimanded. The principle of benevolence is based on the removal of liabilities. An emergency is a situation that justifies less damage to prevent more damage, and there is a lot of talk about a lack of a distressed person's civil liability or a reduction in damages. A person who, in a position of benevolence and when necessary, performs an action that is necessary to prevent damage to another asset, is legally considered a representative and is not responsible without the approval of fault.

Red Crescent relief workers, who inflict damage on the body and property of others while rescuing the injured, should be supported, and their benevolent action should not be accompanied by a civil guaranty. The legal basis for their exemption must be found in the light of legal and jurisprudential principles, while respecting the right of the injured and the owners to guarantee the right to their physical integrity and property. This discussion is also important because the Rescue and Relief Organization, in order to support the services of volunteer rescuers and Red Crescent personnel, usually includes civil liability insurance, according to which, an accident is related to insurance if the action performed to save people and property from the risk of insurance leads to physical injury or death of a third party and the insurer is found liable for compensation. Therefore, the condition for using the insurance is to fulfill the responsibility of the rescuer in accordance with the general rules, and if there are justifiable factors for the fault and it is proved that the rescuer is not responsible, the insurer will not be responsible (5).

\section{Need for professional fault in the civil liability of relief workers}

When a loss occurs, the principle is that the injured party must accept the consequences of the fate and take action to compensate or bear the damage. The other person's liability to the victim is against the rule and it needs to be justified on philosophical, moral, and social grounds. A brief look at the history of the evolution of the principles of civil liability shows that four main theories have prevailed over the rules of civil liability so far, namely a) fault theory, b) risk theory, c) right guarantee theory, and d) mixed and intermediary theories (6). Along with the conventional principles of civil liability, the theory of welfare and social good requires that in cases of lack of fault, the victim should not be left without compensation and the government should act as a provider of welfare to compensate the victims. Moreover, the economic analysis of civil liability, through supporting the theory of distributive justice, suggests that the damage be distributed among all or part of society by imposing liability or compensation on the government.

According to Article 7 of the Transport and Traffic Accident Management Regulations approved by the Public Transport Development and Fuel Consumption Management Working Group approved in 1388, as well as based on the Comprehensive Crisis Management Plan under the title of Comprehensive Rescue Plan, the Red Crescent Society's Rescue and Relief Organization, through its volunteer and trained relief workers, is obliged to conduct search and rescue operations for the injured stuck in traffic and road accidents. In addition, the Penal Code for refusing to help the injured and eliminating life-threatening injuries, approved in 1354, and the executive regulations of the mentioned law, approved by the Council of Ministers in 1364, have determined punishments for refusing to help people at risk of death. In the second paragraph of the mentioned single article, there is a more severe punishment for people who are obliged by duty and law to help injured or exposed to lifethreatening individuals.

The above law is general and includes all individuals, including specialized or nonspecialized and those obliged by law and other factors. Regardless of the fact that the mentioned law states criminal liability in cases of failure to 
provide assistance, the imposition of punishment on these individuals does not preclude liability and financial guarantee of violators, and compensation for victims is subjected to public rules. However, the failure of the responsible persons to perform their duties properly is a kind of fault and the importers of losses, based on this theory, will be held responsible and will be obliged to compensate the damaged parties.

The question that arises here is whether the second paragraph of the single article of the Penal Code for refusing to help the injured is also applicable to the honorary relief workers (those who are required by law or duty to assist the injured people who are obliged by law or duty to help the injured) working with the Red Crescent Society. Some people believe that according to Articles 3 and 6 of the Statute, services are provided by aid workers, and aid workers who are official or contract employees of the Red Crescent Society. Nevertheless, the term "aid workers" seems to apply, and any person who cooperates with the Red Crescent Society on a contractual or honorary basis is subjected to paragraph 2 , who is required by law or duty to assist the injured (2).

Article 953 of the Civil Code states that "fault includes indulgence and misappropriation", and misappropriation is defined by the legislature as "misappropriation is violating from permitted or normal limits in relation to another's property or right" (Article $951 \mathrm{BC}$ ). Indulgence is defined as "the abandonment of an action that is unnecessary by contract or custom to preserve property" (Article 952 BC). As it appears from these definitions, the legislator has paid more attention to contractual liability in them; nonetheless, considering that these two definitions are mentioned in the last book of the first volume of the Civil Code, which is "in different regulations", they are not assigned to contractual liability and can also be used in civil liability.

In addition, according to the note of Article 145 of the Islamic Penal Code, approved in 1392, "Guilt is both recklessness and imprudence. Negligence, incompetence, and non-observance of governmental systems and the like, as the case may be, are examples of recklessness or imprudence." As a result, "non-observance of governmental systems" is considered a fault along with recklessness, imprudence, and incompetence. Consequently, it can be said that according to our laws, a fault is performing (misappropriation) or not performing something (indulgence) that according to the Iranian laws, custom, or contract, a person must avoid or perform.

The criterion for realizing guilt is the conventional human behavior in the event of an accident (7); however, if a person harms another person while performing his/her professional and occupational duties, it is not possible to measure his behavior for the occurrence or non-occurrence of guilt according to conventional human behavior, rather, it should be evaluated in comparison with that of a conventional expert. In case that the cause of the damage is the behavior of a professional in the same job and in the circumstances of the accident, he/she is considered guilty. For example, in evaluating the behavior of a physician, judge, architect, lawyer, or professional player, the criterion for committing a fault is the commission of a professional fault.

Rescuers are also considered professionals who have to rescue in accordance with the rules of the job and previous training, and the criterion for realizing a fault is the behavior of a normal rescuer in the event of an accident. The criterion for measuring his/her behavior is not a normal human being, rather a normal relief worker. In other words, one of the factors that play a significant role in creating or not creating civil liability for relief workers is the normality of their action since it is always necessary that their action be compared with that of other relief forces in similar situations. If that behavior is the same as is performed by other specialized forces in a similar situation and is not contrary to the rules of the regulations, in fact, no fault has been committed by the relevant force and, therefore, no responsibility can be assigned to it.

\section{Responsibility status of emergency physician}

According to Article 495 of the Islamic Penal Code (1392), "If a physician causes loss or bodily harm in the treatment he performs, he is responsible for money compensation unless his action is in accordance with medical regulations and technical standards, or if he is acquitted before treatment and does not commit any fault...". According to Note 1, "If the doctor has not committed a fault in his/her knowledge and practice, there is no guarantee for him/her, even if he/she has not been acquitted."

In fact, according to the famous saying of the 
jurists and Article 322 of the Islamic Penal Code approved in 1370, a physician was responsible without any fault although the treatment was carried out in accordance with the regulations, and he/she was not a guarantor in case of acquittal of the doctor although he/she had committed an unintentional fault. Under current law, a doctor's civil liability is based on fault, even if he/she is acquitted. Of course, in the absence of acquittal of the patient or his parents, in the event of damage as a result of treatment, the legal presumption of guilt applies to the physician unless she/he proves his/her lack of fault by proving medical observance. Moreover, in case of acquittal, the doctor is not a guarantor unless the injured patient proves the doctor's fault (8).

Now, given that the responsibility of relief workers is based on fault and subjected to general rules, that is, the victim must prove the committed fault during the rescue operation and it is his/he responsibility to prove the fault, the question is "If the Red Crescent relief workers are included in the medical staff, are they included in rules general and are they guarantors provided that their fault is proved, or are they subject to special regulations governing physicians and subject to the presumption of fault?" It seems that the aim of the legislator was to impose more strictness on physicians due to the importance of medical work and the relationship between their work and the body and soul of the people and has presumed them to be at fault. With the approval of a special sentence in the Islamic Penal Code, approved in 1392 , every physician, both emergency and nonemergency, is subject to a new special sentence, and Article 1 of the Civil Liability Law cannot be considered applicable to an emergency physician.

Furthermore, according to Article 497 of the Islamic Penal Code, "In emergency cases that acquittal is not possible and the physician treats the patient in accordance with the regulations, no one is liable for the loss or damage." Article 497 seems to have imposed a different sentence on the imposition of the presumption of fault contained in Article 495 of the mentioned law, and in cases that acquittal is not possible, physicians are subject to the general rules of civil liability and are liable if their fault is proved by the injured party. In this respect, in the vast majority of cases, the emergency physician is subject to Article 497 due to the impossibility of acquiring acquittal and the urgent need to save the lives of the injured, and in this respect, the responsibility of nonphysician and physician relief workers is the same.

\section{Rule of Law}

Some titles and factors justify and legitimize the harmful act. In this regard, civil liability based on fault causes the fault to be removed from the harmful act and no liability is created for the person who caused the damage. In fact, the damage is originated from an action that is typically not blamable. Since transgression of normal conduct (indulgence and misappropriation in Articles 951 and 952 of the Civil Code) is a fault, a person who cites one of the justifiable factors of fault is not considered guilty practically.

The rule of law is one of the factors that removes guilt and responsibility because the interests of society and the observance of people's rights require the legislator to establish special rules for the regulation of social events and implement them in a timely manner. Whenever the proper implementation of these regulations harms others, the legislator or the law enforcer is not responsible for compensating the damages because the very implementation of the law is not considered indulgence and misappropriation, even if it is harmful, unless the agent exceeds the limits of legal authority.

Article 1 of the Civil Liability Law states: "If a person, without legal permission, intentionally or as a result of carelessness harms the life, health, property, liberty, prestige, or business reputation of another person or any other right created for an individual by law that causes material or moral damage, he/she is responsible for compensating for the damage caused by his action". According to the mentioned article, one of the most important cases of eliminating the fault, or in other words, one of the reasons justifying the fault, is the infliction of damages with legal permission.

A legal permit, or in other words, a rule of law, must have the conditions to be an obstacle to compensate for both civil and criminal damages. One of the conditions set for the rule of the law is that the law should be valid and enforceable, which means that if a law is drafted and then abrogated or allocated, no action can be taken according to a law that is not enforceable, neither is it possible to pay any damages. 
The second condition considered for the rule of law is that the implementation of the law will remove the responsibility only when the competent authority implements it; otherwise, the law enforcer without the competence to implement the law will be held responsible (7). It should be noted that the executive regulations of the law and administrative instructions are also considered the rule of law and their proper implementation does not create any responsibility as long as the instructions have been issued by a competent authority.

Considering the circumstances and the fact that the relief workers become the source of damage to the injured person or his property in order to perform their duties and responsibilities; if these actions are in line with the performance of their duties and responsibilities, the caused damage is considered justified. Some examples of relief workers' responsibilities are providing relief services in case of natural disasters, such as earthquakes and floods, inside and outside the country, or providing first aid in emergencies by relief workers (Article 3 of the Statute of the Red Crescent Society of the Islamic Republic of Iran).

The relief forces are not responsible for the occurrence of these damages in the normal professional specialty level since they have committed a harmful act with a legal license. Paragraph 3 of Article 7 of the Regulation on Safety Management of Transportation and Traffic Accidents, which indicates one of the duties of the Rescue Organization of the Red Crescent Society, oversees the activities of the rescuers of this society in order to search and rescue the injured and harmed in accidents. As a result, their actions and behaviors are based on the decree of the legislator.

\section{Beneficence}

In Iranian law, beneficence is one of the removals of liabilities (There is no blame on the righteous and is the requital of goodness anything but goodness) and a person who has acted in the position of beneficence (intending to do something expedient and acting conventional manner) is usually not responsible for possible damages against the victim party. Nevertheless, if he/she has acted contrary to the norm, the intention of benevolence is not enough and the benefactor is the guarantor (9).

According to Article 509 of the Islamic Penal Code, "If a person acts in the interests of pedestrians by in accordance with legal regulations and safety points and accidentally causes a crime or damage, that person is not a guarantor." In this sentence, doing something that is in the interest of another, provided that the legal provisions are observed and the damage is not foreseeable and according to the so-called legislature "accidentally causes a crime or damage", does not create responsibility for the perpetrator of the harmful act.

Although the appearance of this sentence is related to expedient action in the passages or public places, it is not specific to the passages and it is an expression of a general rule that the agent is not a guarantor provided that he/she has observed the above four legal conditions. This legal document is not enough to exempt the relief workers since they predict the damage to the injured during the rescue operation and the damage is not an accident that can be considered accidental.

According to Article 510 of the Islamic Penal Code, "Whenever a person, motivated by benevolence and helping another, performs a behavior that is necessary to protect others' property, life, reputation, or honor, and the same act causes injury or damage, if the legal provisions and safety points are observed, he/she is not a guarantor." Regarding this, firstly, the perpetrator must have acted with the motive of benevolence and help; secondly, the action needs to have been taken to protect property or life; and thirdly, legal regulations and safety points have been observed.

In this case, the benefactor is not a guarantor, whether the damage has occurred directly and through an agent or indirectly and causatively. In fact, the mentioned ruling is the expression of the rule of beneficence in Islamic jurisprudence, according to which beneficence is considered one of the causes of the removal of liabilities (There is no blame on the righteous). Of course, according to the general rule of beneficence, the performed act, whether in the position of gaining a benefit or merely repelling harm, is considered benevolence, especially when a loss is inflicted on someone's life.

Considering the type of activity and performance of the relief forces, what comes to mind is that one of the factors exempting the relief forces active in road accidents is the rule of beneficence since the type of their activities often 
includes matters that the norms of the benefactors consider them to be beneficence and the relief forces as benefactors, and as a result, the relief forces have no civil responsibility. According to the appearance and application of Article 510 of the said law, considering the fact that the relief forces typically act with the intention of beneficence and benevolence and the individuals' rights is violated on the same basis, it can be said that the legal basis for the civil liability of the relief forces in harmful acts is the rule of beneficence.

As can be deduced from the provisions of the rule of beneficence and the above-mentioned article, the requirement of the governing of the rule of beneficence on harmful acts is the occurrence of real beneficence. True beneficence refers to the time when both the action of the relief forces is considered beneficence and the relief forces have the intention and motive of beneficence and charity. According to the type of activity of the relief forces, from the public and rational point of view, the actions of the relief workers are considered an act of altruism and charity, and the actions of these forces are based on beneficence. Nonetheless, is it possible to explain with certainty that all the relief workers have the intention of beneficence and charity? Is a person who, by contract or law, has the duty of rescuing others and in line with the same duties, rescues them, even though with the intention of beneficence, is subject to the rule of beneficence or should his irresponsibility be included in the provisions of the agreement or the rule of law?

It can be stated that Article 510 of the Islamic Penal Code, approved in 1392, includes any person, is applied to any person, including the relief forces and other ordinary people in the society. However, the rule of beneficence seems to have been arisen from a person's action that is typically beneficence in accomplishing a legal or contractual duty. The legislator, according to the regulations governing the relief forces, obliges them to perform the relief duty and save the lives of others in their operations, and even criminalizes their abandonment of those actions, and considers violator to be punished, In this respect, it seems that the application of "any person" in Article 510 of the Islamic Penal Code, approved in 1392, is arisen from people who are obliged to do something according to their duties and law, and the purpose of the legislator is to encourage other members of society that lack a legal duty to help others.

It is clear that the general public considers people as benefactors, such as relief workers that do not spare any effort to save people in their relief missions. However, it should be noted that the relevant forces act in accordance with their legal duties and the good respect and recognition of the public do not exempt them from their legal duties. Therefore, in the absence of sufficient expertise and knowledge and infliction of harm to individuals, the named mentioned individuals are responsible and have to compensate the loss according to the general and rule of loss.

It may be possible to distinguish between volunteer relief workers, who dedicate themselves to perform rescue operations, and rescuers, who have employment contracts or are paid for their work. The first group is subject to the rule of beneficence, while the second group is subject to the general rules. It seems that the purpose of applying the rule of beneficence is to exclude the benefactor from the rule of liability presumption (tort) for possession. Relief workers, according to the law, are allowed to carry out rescue operations and their consequences, which causes material and physical damage, and the inclusion or noninclusion of them in the beneficence rule does not affect their responsibility.

\section{Managing others' affairs}

The management of others' property is when a person manages one or more property or assets belonging to another for his/her own benefit (4), without being represented by him/her. According to Article 306 of the Civil Code, "If a person manages the properties of a missing or confiscated and the like person without the permission of the owner or the person who has the right to permit, he must account for his tenure. If obtaining permission was possible in time or delay in intervention did not cause harm, it will not have the right to demand expenses. However, if the lack of intervention or delay in intervention causes damage to the owner of the property, the intervener will be entitled to receive the expenses that were necessary to manage".

According to the principle of non-guardianship over others, a person cannot interfere in the financial and non-financial affairs of others unless he is authorized, has a power of attorney, or is a legal or judicial representative. Sometimes a person manages another person's property without 
the permission of the owner and without legal representation or contract; in this case, by summing the following conditions: interference, benevolent intervention, interference with the intention of beneficence or administration for another, the owner's inability to manage, and the necessity of administration, the benevolent manager is considered a representative by law and is entitled to receive the expenses necessary for the administration.

Some scholars believe that Article 306 is an example of the rule of beneficence and its spiritual element is the intention of beneficence (3). However, this view has been criticized: (10) "With careful consideration in this article and the discussions that were stated in the rule of beneficence, it becomes clear that the following assumption of the article is not an example of the rule of beneficence since in the said assumption, if in case of non-interference or delayed interference causes harm to the owner of the property, and the person interferes with this presumption and incurs expenses through it, the owner of the property will be the guarantor of the payment of these expenses.

Nevertheless, as it has been said, beneficence is the removal of liabilities, and Islamic jurists have also stated this. According to their theory regarding the person who acts out of benevolence and his act leads to damages, that person is neither the guarantor of the damages nor the creditor of the imposed expenses. In other words, the rule of beneficent is the removal of liabilities not the cause of it". In any case, if beneficent is not one of the foundations of the theory of benevolent intervention in managing other people's property, it cannot be denied that one of the conditions for the legal representation of the manager for the management of other assets is the existence of beneficence intention.

It seems that this law is related to financial affairs and is not considered a license to manage other' non-financial affairs. However, some professors (3) believe that the intrusive management of non-financial property also includes non-financial matters, unless interfering in it harms the honor and private family relations. In this case, it may be possible to allow the relief workers to manage others' properties within the framework of benevolent intervention.

Nevertheless, this theory cannot justify the rules and effects of rescue operations because, on the one hand, relief workers have the task of rescuing by law and contract, and failure to act brings about liability and leads to criminal liability. However, the manager is not obliged to benevolent intervention in another's asset, and he is a representative in case of acting in accordance with the law. On the other hand, the benevolent intervention manager can claim the costs from the owner, and the execution of the contracts entered into by the benevolent intervention manager is basically with the owner; nevertheless, the rescuers do not have the right to demand the cost of the rescue operation from the injured.

Urgency refers to a set of circumstances that cause a person to intentionally harm another in order to avoid greater harm, despite his inner desire. In fact, it is a situation in which a person inevitably inflicts less harm on another in order to protect him/herself from another existing or imminent harmful danger (11). According to the principle of constraint, which has been approved by various legal systems regarding criminal liability and has always been considered (including Article 152 of the Islamic Penal Code, approved in 1392), anyone who deliberately commits a criminal act in order to do something necessary should not be blamed and punished.

This occurs in a situation that poses a serious threat to the life or rights of the perpetrator and the only way to get rid of it is to commit a criminal act. In the Islamic legal system, the principle of constraint "necessities explain excuses" has justified the commission of a crime in a state of emergency. Cases have also been considered for the realization of emergencies, and if these circumstances are combined, the person who caused the loss will be considered distressed.

In order to cite urgency as a factor of exemption, several conditions are necessary. The first necessary condition for urgency is that the state of necessity is present and not merely likely to occur in the future. That is to say, in cases of relief in the event of an accident, the rescue force is allowed to take action contrary to the rights of others when the current situation poses an unusual danger to the person or another.

In other words, the relevant rescuer cannot ignore the rights of individuals simply because there is a possibility of injury to the person at risk and commit a harmful act; rather, the danger must be imminent so that any conventional rescuer feels the situation in such a way that if no action is taken to release or rescue the injured person, the 
damage or loss of inevitable compensation will certainly occur. The second necessary condition is to pay attention to the fact that there is no other way out for the distressed person (i.e., rescuer). That is, if the relevant rescuer, can prevent the danger created for the injured person in another way, he has no right to harm another person. In other words, custom expects a specialized and committed relief force, in the event of an accident, to perform its relief duty as much as possible, in a way other than infringing on the rights and property of individuals and save lives, rather than performing a hurried action in the scene of the accident, like a non-specialist, and causing physical or material damage to the rights of other people with this action.

In numerous road accidents, people are usually injured in accidents and depending on the type of accident, they are trapped in their car, so that the public, at the first time of seeing the accident, think that the only way to release the injured person from the car is to cut the vehicle in which the injured person is trapped. An expert and trained force should consider this action the last way to save the injured person and examine other available ways, and if the only way to save the injured person is damaging the car, take action.

For example, in an accident in which the driver is trapped due to the overturning of a car and the rescuer is present at the scene and his initial examination indicates only a minor and noncritical injury to the injured person (i.e., sending him to the medical center is not very urgent) and the situation of the accident is such that the car door does not open due to the severity of the accident, it should be noted that if the delay in sending him to the medical center does not harm the health of the injured person, the rescuer should try to release the injured through other means than using hydraulic scissors.

The distressed person must suffice as much as he can to meet the necessity, act as much as necessary, and suffice to the extent that it removes harm from himself or another person. With this explanation, a rescuer who has sufficient knowledge and expertise in releasing the injured in a road accident and is helping the injured person in a car overturning accident, and the upcoming accident is one of the cases where the only way to release the injured person from inside the car is cutting and damaging the car, he should take action that has the least amount of damage to the vehicle.

The jurisprudential rule of "Necessity must only be assessed and answered proportionately" also shows this. Obviously, because the relief workers must be professional in rescuing, and the criterion for finding fault is the behavior of a normal specialist, any criterion for the violation of the behavior of a specialist rescuer is the professional fault, and the rescuer without the necessary skills is considered a deterrent and the rescue organization as his employer is liable for the loss (Article 12 of the Civil Liability Law).

In our law, Article 55 of the former Islamic Penal Code used to read: "Anyone who commits a crime in the event of a serious danger, such as a flood or storm, in order to save his/her life or property or that of another, shall not be punished, provided that he/she did not create the danger intentionally and his act was proportionate to the existing danger and was necessary to remove it." However, its note adds: "Money compensation and financial guarantee are exempt from the provision of this article". The exception in this note was justified as follows: on the one hand, the state of emergency does not allow the injury to the physical integrity of man, and on the other hand, in the event of damage to property, although the state of emergency eliminates the commission of a fault on the part of the distressed person, it does not mean that he, for example, become the guarantor of the loss to compensate because in our law, In our law, the wasteful responsibility is not based on fault.

The provision of the note of Article 55 of the Islamic Penal Code is not mentioned in the previous law: Article 152 of the Islamic Penal Code, approved in 1392, stipulates: "Anyone who, in the event of a present or imminent danger, such as a fire, flood, hurricane, earthquake, or disease, commits an act that is considered a crime in order to save his/her life or property, is not punishable as long as he/she does not intentionally create the danger and the fault is commensurate with the existing danger and is necessary to avert it.

Note: Those who are obliged to deal with danger according to their duty or law cannot refuse to perform their legal duties by relying on this article".

It seems that for the above reasons it should still be believed that in the urgency of money compensation and financial guarantee, in other 
words, civil liability is in principle. Note 3 of Article 156 of the Islamic Penal Code states: "In cases of legitimate defense, the money compensation is also void, except in the case of defense against a mad attack, in which the money compensation is paid from the Bayt al-mal". The legislative silence can be used as a statement under urgency, which is eliminated among the justifiable factors of crime in the legitimate defense of civil liability; however, this does not apply to urgency, and the issue of urgency should be analyzed under the discussion of misuse. The omission of the note should also be interpreted in the light of the nature of the compulsory guarantee of the subject and its lack of connection with criminal matters.

However, the verdict is not always the same, and based on misuse, the distressed person is not responsible for compensation and the injured party refers to the person who has used the emergency situation. In fact, four assumptions can be imagined in an emergency: one, the infliction of damage to another to repel the loss from a third party, in which the injured party refers to the third party who used this situation, not to the person who caused the damage, who was in distress; second, the infliction of damage to another to repel the loss from the injured party, where the two descriptions of the beneficiary and injured party are combined in one person and the issue of recourse is eliminated; third, injuring oneself to repel the loss of another, in which case the injured and distressed persons are the same and he refers to the beneficiary of the emergency situation; and fourth, the infliction of loss on another to repel the loss from oneself, in which the two descriptions of the cause of distressed person and the beneficent are summed up in a single person, and the victim refers to the person in distress. In any case, referring is to the extent that the beneficiary has used, not to the extent of the damage to the injured party.

To better explain the issue, we examine two assumptions that are common in traffic accidents: First: harm a person to prevent harm from him. If a person harms a person in an emergency condition to prevent a bigger loss, he is not responsible, such as when relief workers harm the injured person to repel more important harm from him. Regarding this, it is not appropriate to consider a relief worker responsible when, for example, a person who is suffering from severe bodily harm and is trapped in his/her car and will not be released from the most important danger (death) unless by the release operation that is merely achieved by damaging.

In some cases, the only way to rescue the injured person stuck in his vehicle is by breaking the car window and transferring him to a safe place, and the rescue force will do so immediately. In such a situation, the relief worker should not be held responsible for the damage since the only way to save the injured person from a dangerous situation was to damage his car, and the relevant rescuer had no choice to save the injured person but to intentionally destroy the glass of his car. Second: harm a person to repel another harm. In this case, the person harms the other to prevent greater harm to the third party, such as when rescue workers are forced to inflict damage on a third party to save another person's life. It is very common that in road accidents, people who are inside a vehicle and have an accident do not own a vehicle, such as a car that transports passengers on intercity routes.

In this situation, if the car has a traffic accident and one of the passengers needs immediate help so that the only way to save the life of the injured person is to intentionally destroy the car, is this action necessary for the rescue force considering that he is not the owner of the vehicle and the saving of his life depends on the intentional destruction and damage to another person? Pursuant to Article 152 of the Islamic Penal Code and provided that the relief force has acted in accordance with the above, the above-mentioned criminal punishment for committing the crime of intentional destruction is negative to the annulment of the case.

\section{Methods}

This descriptive-analytical research describes the subjects or phenomena and their conditions and elements. Considering that to conduct research and explain the content, the provision of legal analysis is based on the analytical method, the method of data analysis is also based on the logical analysis. In this research, documents at traditional and digital libraries were used for data collection and notetaking was employed as the tool to gather data.

\section{Findings}

Rescuers, whether they work voluntarily or unpaid or are employed under a replacement 
contract, whether they are physicians or not, are required to inflict bodily or financial damage on the injured or others in order to carry out rescue operations. However, their legal status is not the same in terms of liability for losses resulting from relief operations. The responsibility of the rescuers is basically based on fault; nevertheless, the emergency physicians are subject to the presumption of the fault and a special sentence, unless they cannot be acquitted due to the necessity and urgency of rescue, in which case they are subject to general rules.

The examination of the grounds for liability exemption and the justifiable factors of fault on the part of the relief workers shows that although they typically act in a beneficence manner, they cannot be exempted from liability on the basis of benevolence, except the volunteer rescuers. The rulings and effects of the benevolent intervention of others' affairs also show that it is difficult to apply the title of benevolent intervention manager to the rescuers. Nonetheless, in some cases, where rescuers are forced to inflict less damage on the more important damage, the person who has benefited from the emergency is liable to the victim. Finally, the main basis for the exemption of rescuers should be considered the rule of law, which allows them to carry out rescue operations, and the damages associated with rescuing the injured are in accordance with the rule of "permission in the object results in permission in its consequences", cannot be claimed from rescuers.

\section{Discussion and Conclusion}

A rescuer is a person who rescues the injured according to the law and within the framework of legal regulations, is in a position of beneficence, and is in distress, causing less damage to repel more important damage. Sometimes he manages the property of the injured when necessary. Therefore, the rule of beneficence, the rule of law, benevolence intervention, and urgency can be considered as factors in relieving aid workers.

However, matching the situation of the rescuers with the justifiable factors shows that the main basis of the rescuers' exemption is the rule of law, which gives them the authority and duty to carry out rescue operations, and the necessary damages to rescue the injured is based on the rule of "permission in the object results in permission in its consequences". The existence of inherent risk in relief activities requires the relief workers' civil liability insurance, and that the basis of liability be changed from some form of fault (exceeding normal human behavior) to no-fault liability (danger). This facilitates relief efforts and guarantees the rights of victims.

In fact, it should be said that rescuers' liability insurance should be mandatory and insurance costs should be imposed on all car owners under third party car insurance, which is necessary for the distribution of damages and the realization of distributive justice and facilitates providing assistance to the injured in traffic accidents, providing compensation to the victims, and ultimately, ensuring social welfare and well-being.

\section{Acknowledgments}

The authors would like to express their gratitude to all those who contributed to the conduction of this research project.

\section{Conflict of Interests}

Authors declared no conflict of interests regarding the publication of the present study.

\section{References}

1. Omidifard, A, Jokar SM, Arab Ahmadi MR. Jurisprudential-Legal Analysis of Rescue and Relief. Scientific journal of Rescue and Relief 2014; 6: 7691. (In Persian)

2. Mansouri S, Afchangi M. Helping and assisting others Ethical and legal principles, responsibility of individuals, existing challenges. Scientific Quarterly of Rescue 2009; 3: 26-39. (In Persian)

3. Katoozian N. Civil Liability due to driving accidents. 9th Ed. University of Tehran Press; 2011. (In Persian)

4. Katoozian N. Civil Law (Legal Events). 14th ed. Sahami Enteshar publication; 2008. (In Persian)

5. Relief and Rescue Organization. Red Crescent Civil Liability Insurance Policy. 2016. Available from: https://raro-ir.translate.goog/images/PDF/Dastor/ Madani.pdf? (In Persian)

6. Badini H. Philosophy of Civil Liability. 1th ed. Sahami Enteshar publication; 2005. (In Persian)

7. Qasemzadeh SM, Principles of Civil Liability. 5th ed. Dadgostar publication; 2008. (In Persian)

8. Kazemi M. Review the idea of the responsibility of physician, in Islamic jurisprudence (FIQH): a chronological study. Quarterly Journal of Politics: Journal of the Faculty of Law and Political Science 2010; 40: 275-95. (In Persian)

9. Yazdanian A, Niazi A. Investigating the civil liability of relief workers due to use of animals in relief operations. (In Persian)

a. Scientific journal of Rescue and Relief 2018; 9: 54-67. (In Persian)

10. Mousavi Bojnourdi SM. Rules of Jurisprudence. 2nd ed. Majd Publications; 2008. (In Persian)

11. Safaei SH, Rahimi H. Civil Liability (Non-Contractual Requirements). 2nd ed. Samt Publications; 2011. (In Persian) 